\title{
A Rare but Fatal Complication of PEG: Buried Bumper Syndrome (BBS)
}

\author{
Kyawzaw Lin ${ }^{1}$, Jad Sargi ${ }^{2}$, Aung Naing Lin ${ }^{1}$, La Min Phyu ${ }^{3}$ and Khin Myint ${ }^{4}$ \\ ${ }^{1}$ Internal Medicine Department, The Brooklyn Hospital Center, Affiliate of the Mount Sinai Hospital, 121, Dekalb \\ Avenue, Brooklyn, NY 11201, USA \\ ${ }^{2}$ Critical Care Fellow, The Brooklyn Hospital Center, Affiliate of the Mount Sinai Hospital, 121, Dekalb Avenue, \\ Brooklyn, NY 11201, USA \\ ${ }^{3}$ University of Medicine (1), Yangon, Myanmar
}

${ }^{4}$ Attending Physician, Internal Medicine Department, The Brooklyn Hospital Center, Affiliate of the Mount Sinai Hospital, 121, Dekalb Avenue, Brooklyn, NY 11201, USA

Received: July 03, 2018; Accepted: July 23, 2018; Published: July 25, 2018

*Corresponding author: Kyawzaw Lin, Department of Medicine, The Brooklyn Hospital Center, 1733 West 1st Street, Brooklyn, NY 11223, USA, Tel: 315664-1916; E-mail: dr.kyawzawlin2015@gmail.com

\begin{abstract}
Percutaneous endoscopic gastrostomy(PEG) are used for long -term enteral feeding. Buried bumper syndrome (BBS) is one of the rare but life- threatening complications of PEG placement. BBS is defined as migration of inner bumper (fixating internal part of PEG) along the stoma channel from the bumper partially covered by overgrowth mucosa to complete dislodgement of bumper outside the gastric wall. Here, we present a 72- year- old nursing home resident with complete BBS.
\end{abstract}

\section{Introduction}

Buried Bumper Syndrome (BBS) is defined as migration of inner bumper (fixating internal part of PEG) along the stoma channel. The bumper may be partially covered by over-growth mucosa or completely dislodged outside the gastric wall. Complete BBS without visible part of inner pumper can be a challenge for endoscopic management. Here, we present a 72year- old nursing home resident with complete BBS.

A 72-year-old- nursing home male resident was sent from nursing home for a dislodged PEG tube. Past medical history was pertinent for type 2 diabetic mellitus, hypertension, stroke with left sided hemiparesis and dementia. PEG was placed in setting of advanced dementia and dysphagia from CVA 6 months ago. Vitals were stable. Labs were within normal references. On local examination, stoma showed signs of infection. The external pumper was more than $1 \mathrm{~cm}$ from the stoma and internal bumper was juxtaposed to the skin under the stoma cavity. Flushing of the PEG tube with normal saline elicited painful withdrawal of hands. CT abdomen showed the internal bumper of the PEG tube was located between the abdominal wall and anterior wall of the stomach compatible with buried bumper syndrome (Figure-2). Inner bumper was removed. Under appropriate antibiotics, another PEG reposition was performed without complication (Figure-3). The patient tolerated tube feeds and was disposed to nursing home.
BBS can be presented with a symptomatic clinical triadinability to insert food or liquids, loss of patency and peristomal leak. In our case, the patient was successfully managed with PEG tube reposition through guided wire via the original track without complications.

Key words: Buried Bumper Syndrome; PEG (Percutaneous Endoscopic Gastrostomy); Gastroenterology;

\section{Case Presentation}

A 72-year-old- nursing home male resident with past medical history of Type 2 diabetic mellitus, hypertension, stroke with left sided hemiparesis and dementia was sent from nursing home for a dislodged PEG tube. PEG was placed for advanced dementia and dysphagia due to stroke 6 months ago. Vitals were stable. Complete blood count, comprehensive metabolic panel and coagulation panel were within normal references. On local examination, stoma showed signs of infection. The external pumper was more than $1 \mathrm{~cm}$ from the stoma and internal bumper was juxtaposed to the skin under the stoma cavity. Flushing of the PEG tube with normal saline elicited painful withdrawal of hands. XR (Abdomen) showed moderate constipation with multiple prominent bowel loops (Figure-1). CT (abdomen) showed internal bump of the peg tube appears to be between the abdominal wall and anterior wall of the stomach compatible with buried bumper syndrome (Figure-2). There is large right renal cysts. Copious fecal matter suggestive of constipation.Degenerative changes of the visualized thoracolumbar spine with fusion at L 1-2 as well as old fracture of L2. Pre-operative bedside examination showed both the internal/external bumpers were intact. BBS was removed. Under appropriate pre-operative antibiotics, another PEG reposition was performed without complication (Figure-3). The patient tolerated tube feeds the next day and was disposed to Nursing home. 


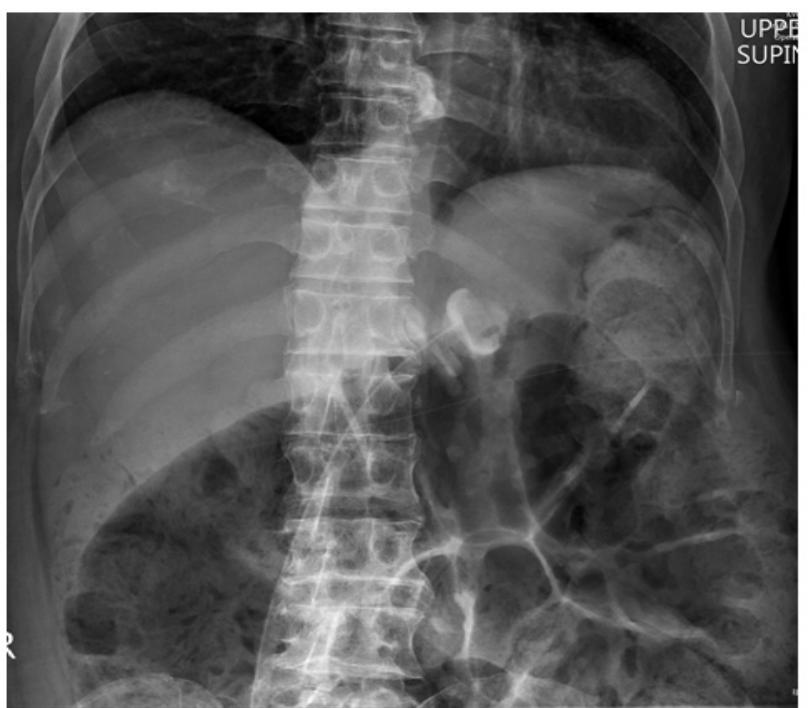

Figure 1: XR (Abdomen) showed moderate constipation with multiple prominent bowel loops

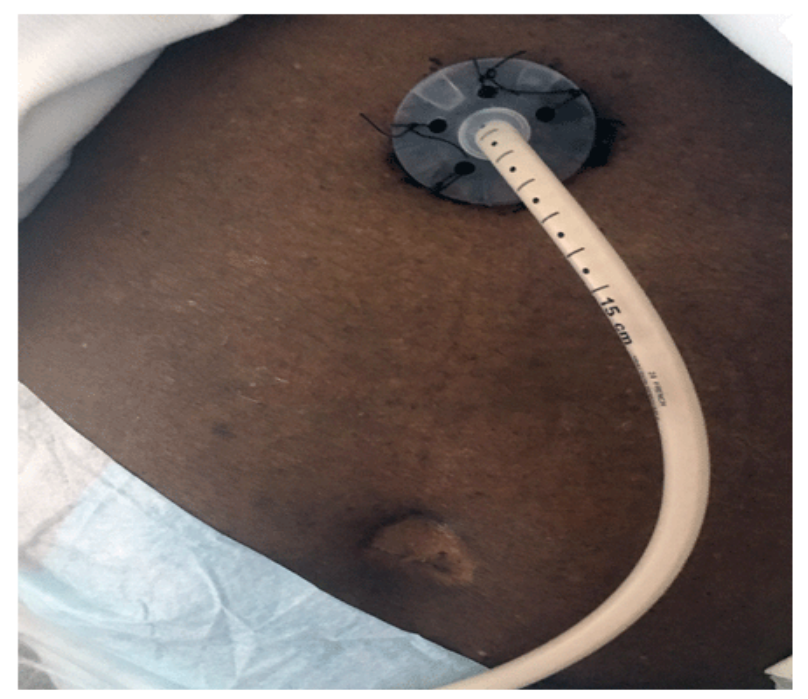

Figure 3: New percutaneous endoscopic gastrostomy (PEG).

\section{Discussion}

Percutaneous endoscopic gastrostomy (PEG) is performed for long term enteral feeding indicated for neurological and neurodegenerative disorders that result in impaired swallowing. With the up-trending requirement for PEG, the increasing numbers of buried pumper syndrome are reported in the literature. BBS is usually early complications of PEG (within 30 days of PEG placement) but can be found as late complications (months to years after the procedure). The incidence is reported in $0.3-2.4 \%$ of PEG. The risk factors for BBS include severe protein energy malnutrition, prolonged steroid uses, patients with underlying malignancy or patients undergoing chemoradiation therapy [1].

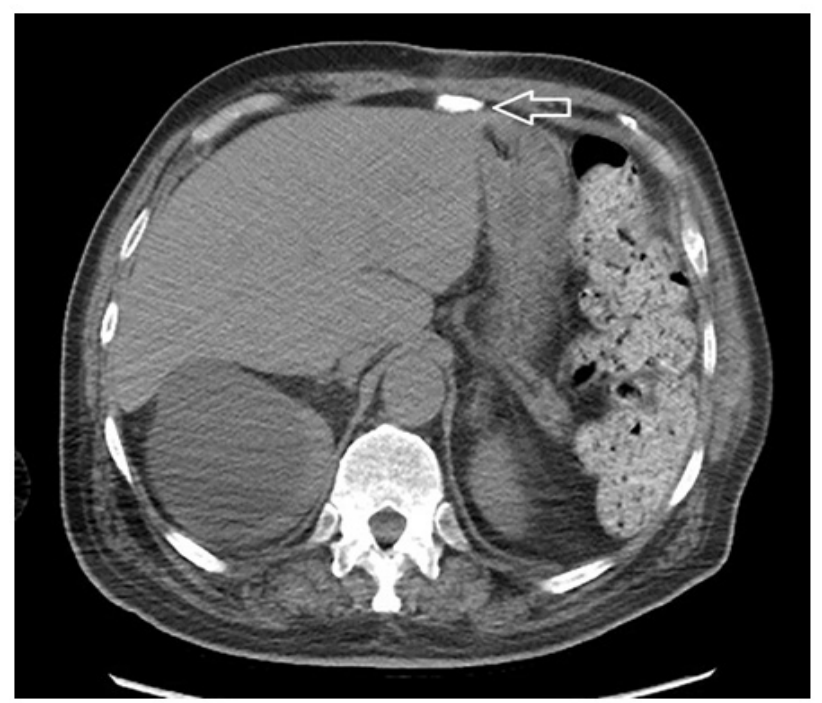

Figure 2: CT abdomen showed the internal bumper of the PEG tube was located between the abdominal wall and anterior wall of the stomach compatible with buried bumper syndrome.

The complications of BBS include gastrointestinal bleeding, perforation, peritonitis, and sepsis with or without septic shock from intraabdominal wall abscess. BBS can be presented with a symptomatic clinical triad- inability to insert food or liquids, loss of patency and peristomal leak $[1,2]$. Severity of BBS is categorized according to depth of invasion in endoscopy and imaging [3].

Incomplete BBS is defined as BBS with visible parts of inner bumper and does not usually create a serious problem. It can be managed with extraction with the foreign body grasping forceps in most cases. However, in case of deeply ingrown pumper, endoscopic push techniques (using Savary Bougie or biopsy forceps), papillotome-based techniques or pull-techniques (Foreign-body grasping forceps) [4, 5].

Complete BBS is defined when the inner bumper cannot be visible. In complete BBS, CT scan or endoscopic ultrasound can be used to visualize the anatomy of bumper such as depth of invasion and extra-gastric or intramural localization. Extragastric pumpers are usually managed surgically. For internal bumper localized in the gastric wall, endoscopic treatment such as endoscopic push or pull techniques or papillotome-based techniques are done by experienced interventionists [6].

Different approaches have been reported in the literatures for early BBS. It includes to leave or not to leave buried bumper. Some suggested repositioning of the buried bumper into the gastric lumen. Others recommend extraction of buried bumper and placement of a new PEG tube through the same or adjacent tract with the following techniques: (1)via the guidewire to the gastric lumen with endoscope, reposition can be done using a bougie or a hydrostatic balloon dilator ; (2) using a gasper under the guidance of endoscope; (3) through radial incision made over the bumper using a wire guided papillotome after guidewire 
recannulation of gastric wall $[7,8,9] ;(4)$ via star like radial incisions of gastric wall using a needle -knife; (5) reposition with a thin gastroscope through PEG tube using rotational movements under direct vision [10];(6)external removal of bumper through radial incisions in anterior abdomen wall[11] and (7) under fluoroscopic assistance, reposition of the bumper with stiff guidewire or bougie. However, in complicated cases with sepsis, peritonitis or fistulas, laparotomy and surgical removal of buried bumper is a must.

\section{Conclusion}

BBS can lead to complications such as gastrointestinal bleeding, perforation, peritonitis, sepsis and/or septic shock from intra-abdominal wall abscess. In our case, the patient was successfully managed with PEG tube reposition via guided wire through the original track without complications.

\section{References}

1. Cyrany J, Rejchrt S, Kopacova M, Bures J. Buried bumper syndrome: A complication of percutaneous endoscopic gastrostomy. World J Gastroenterol. 2016;22(2):618-627. doi: 10.3748/wjg.v22.i2.618

2. Ata A Rahnemai-Azar, Amir A Rahnemaiazar, Rozhin Naghshizadian, Amparo Kurtz, and Daniel $\mathrm{T}$ Farkas. Percutaneous endoscopic gastrostomy: indications, technique, complications and management. World J Gastroenterol. 2014;20(24):7739-7751. doi: 10.3748/wjg. v20.i24.7739

3. Richter-Schrag, Hans-Jürgen, Sabine Richter, Olaf Ruthmann, Manfred Olschewski, Ulrich Theodor Hopt, et al. Risk factors and complications following percutaneous endoscopic gastrostomy: a case series of 1041 patients. Can J Gastroenterol. 2011;25(4):201-206.
4. Klein, Samuel, Bruce R. Heare, and Roger D. Soloway. The buried bumper syndrome": a complication of percutaneous endoscopic gastrostomy. American Journal of Gastroenterology. 1990;85(4):448450.

5. Boyd JW1, DeLegge MH, Shamburek RD, Kirby DF. The buried bumper syndrome: a new technique for safe, endoscopic PEG removal. Gastrointestinal endoscopy. 1995;41(5):508-511.

6. Casper M, Lammert F. How to improve success rates of endoscopic management for buried bumper syndrome. QJM. 2018;111(7):467472. doi: 10.1093/qjmed/hcy081

7. Mueller-Gerbes D, Hartmann B, Lima JP, de Lemos Bonotto M, Merbach C, Dormann A, et al. Comparison of removal techniques in the management of buried bumper syndrome: a retrospective cohort study of 82 patients. Endosc Int Open. 2017;5(7):E603-E607. doi: 10.1055/s-0043-106582

8. Christiaens P, Bossuyt P, Cuyle PJ, Moons V, Van Olmen A. Buried bumper syndrome: single-step endoscopic management and replacement. Gastrointest Endosc. 2014;80(2):336. doi: 10.1016/j.gie.2014.04.053

9. Krzysztof Kurek, Andrzej Baniukiewicz, and Agnieszka ŚwidnickaSiergiejko. Buried bumper syndrome: a rare complication of percutaneous endoscopic gastrostomy. Wideochir Inne Tech Maloinwazyjne. 2015;10(3):504-507

10. MM Taher, NR Kosai, and HS Gendeh. Creative treatment of early buried bumper syndrome. Ann R Coll Surg Engl. 2014;96(8):621-622. doi: $10.1308 /$ rcsann.2014.96.8.621b

11. Benatta MA. The buried bumper syndrome: external bumper extraction after radial mini incisions and replacement through an adjacent tract. Case reports in medicine. 2016;3. 